\title{
Evaluation of Magnetite Nanoparticle-based Toxicity on Embryo- Larvae Stages of Zebrafish (Danio rerio)
}

\author{
Anna Jurewicz ${ }^{\star a}$, Shaista Ilyas ${ }^{\ddagger a}$, Jasleen Kaur Uppal ${ }^{\mathrm{a}}$, Ivan Ivandic ${ }^{\mathrm{b}}$, Sigrun Korsching ${ }^{\mathrm{b}}$, and Sanjay Mathur*a \\ a Institute of Inorganic Chemistry, University of Cologne, Greinstr. 6, 50939 Cologne, Germany \\ b Institute for Genetics, University of Cologne, Zülpicherstr. 47a, 50674, Cologne, Germany \\ *Correspondence: sanjay.mathur@uni-koeln.de; Tel: +49 2214705627 \\ Fqual contribution
}

\section{Contents:}

Figure S1. Survival rate of zebrafish embryos with and without chorion at different concentrations of $\mathrm{CR} @ \mathrm{Fe}_{3} \mathrm{O}_{4} \mathrm{NPs}, \mathrm{Fe}_{3} \mathrm{O}_{4} \mathrm{NPs}$, and pure Congo red dye.

Figure S2. ${ }^{1} \mathrm{H}$ NMR spectra of Schiff base ligand (SBCR)

Figure S3. ${ }^{13} \mathrm{C}$ NMR spectra of Schiff base ligand (SBCR)

Figure S4. DLS measurement of $\mathrm{Fe}_{3} \mathrm{O}_{4}$ NPs with PDI measurements.

Figure S5. Zeta potential of $\mathrm{Fe}_{3} \mathrm{O}_{4} \mathrm{NPs}$.

Figure S6. Zeta potential of Congo red.

Figure S7. Zeta potential of $\mathrm{CR} @ \mathrm{Fe}_{3} \mathrm{O}_{4} \mathrm{NPs}$.

Figure S8. SEM image of iron oxide NPs. 

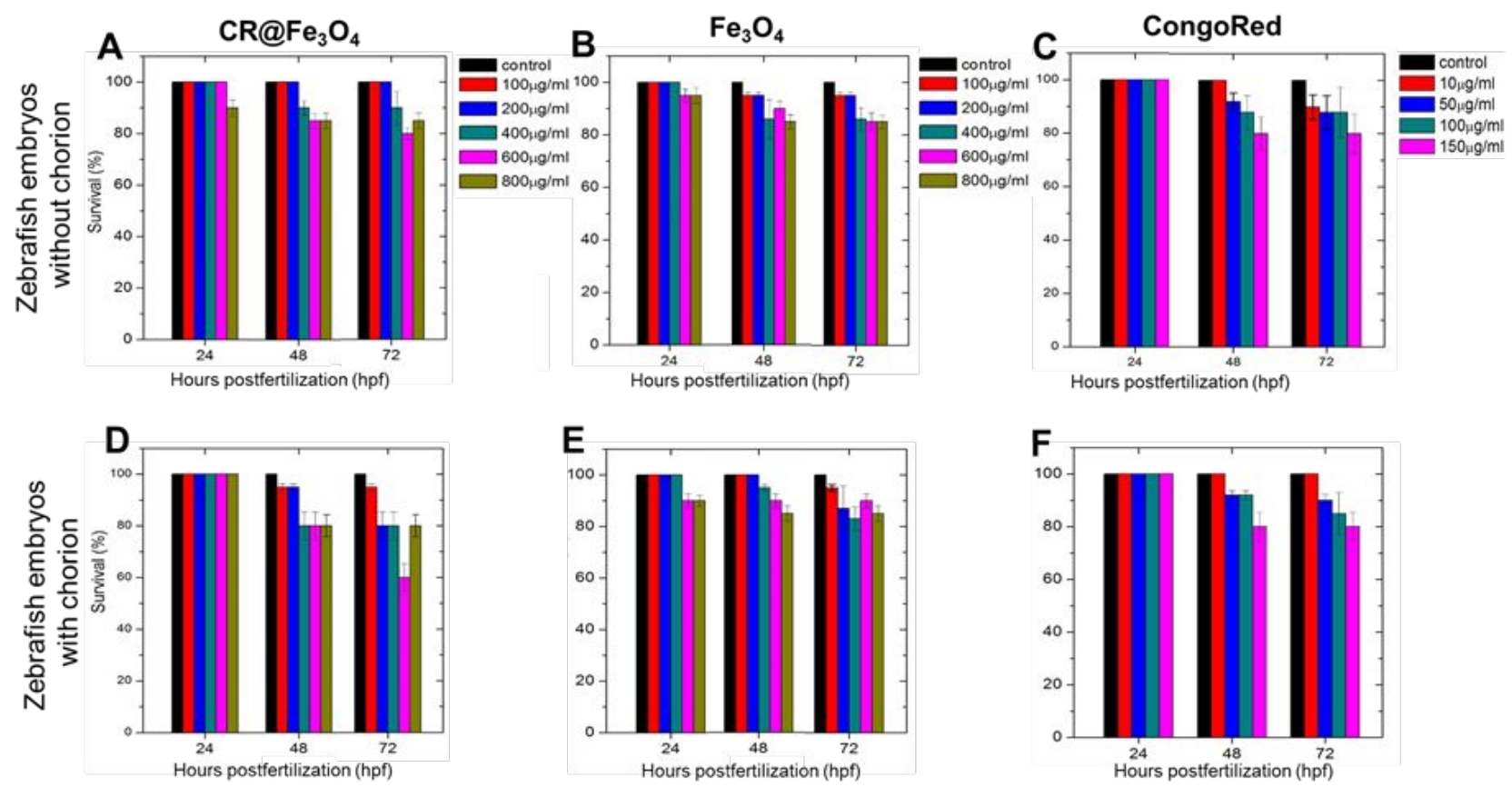

Figure S1. Survival rate of zebrafish embryos without chorion (A-C) and with chorion (DF) exposed to different concentrations of $\mathrm{CR} @ \mathrm{Fe}_{3} \mathrm{O}_{4}(\mathrm{~A}, \mathrm{D}), \mathrm{Fe}_{3} \mathrm{O}_{4}(\mathrm{~B}, \mathrm{E})$, and pure Congo Red (C,F). The measurements were taken after $24 \mathrm{~h}, 48 \mathrm{~h}$ and $72 \mathrm{~h}$. 


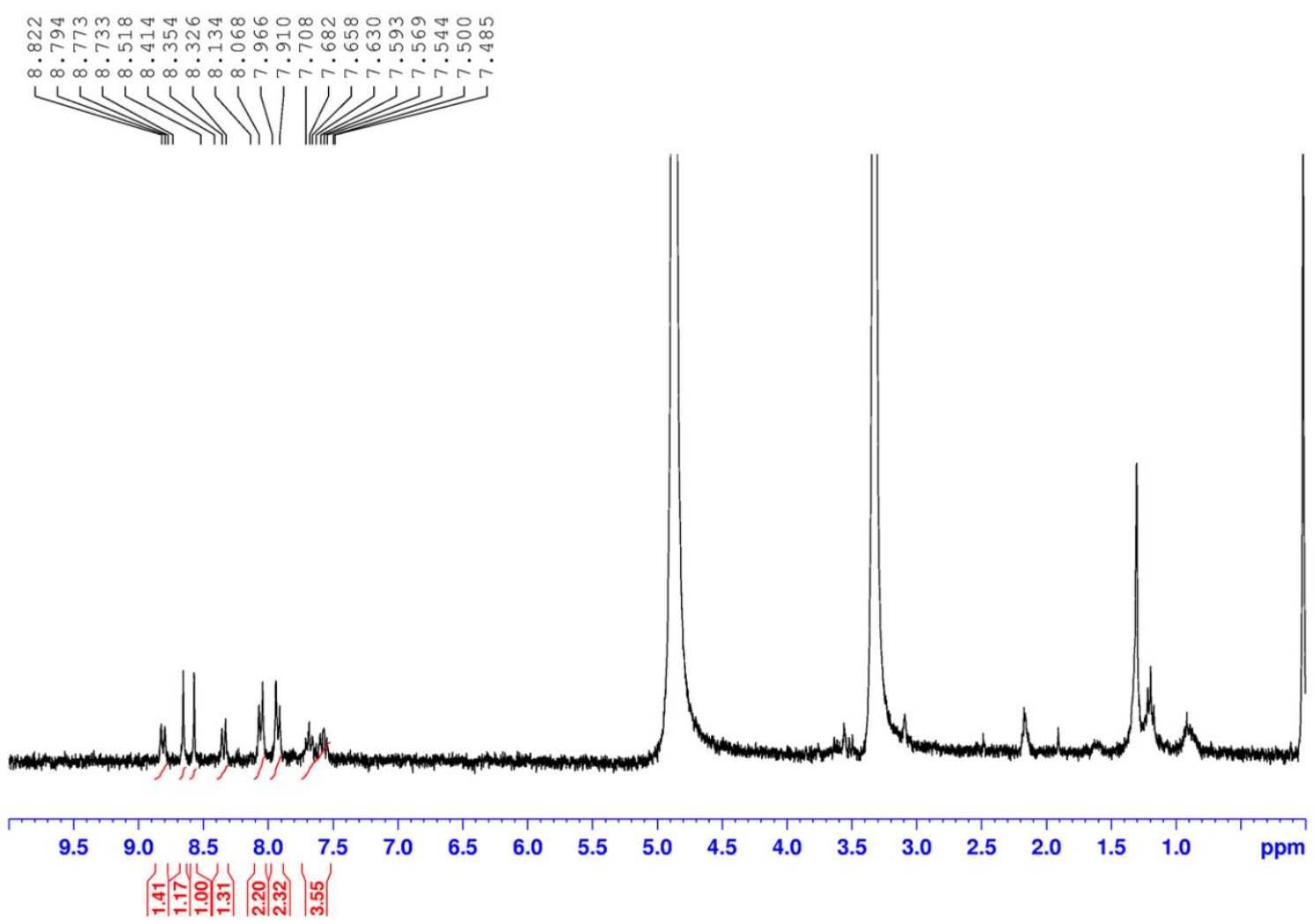

Figure S2. ${ }^{1} \mathrm{H}$ NMR spectra of Schiff base ligand (SBCR) 


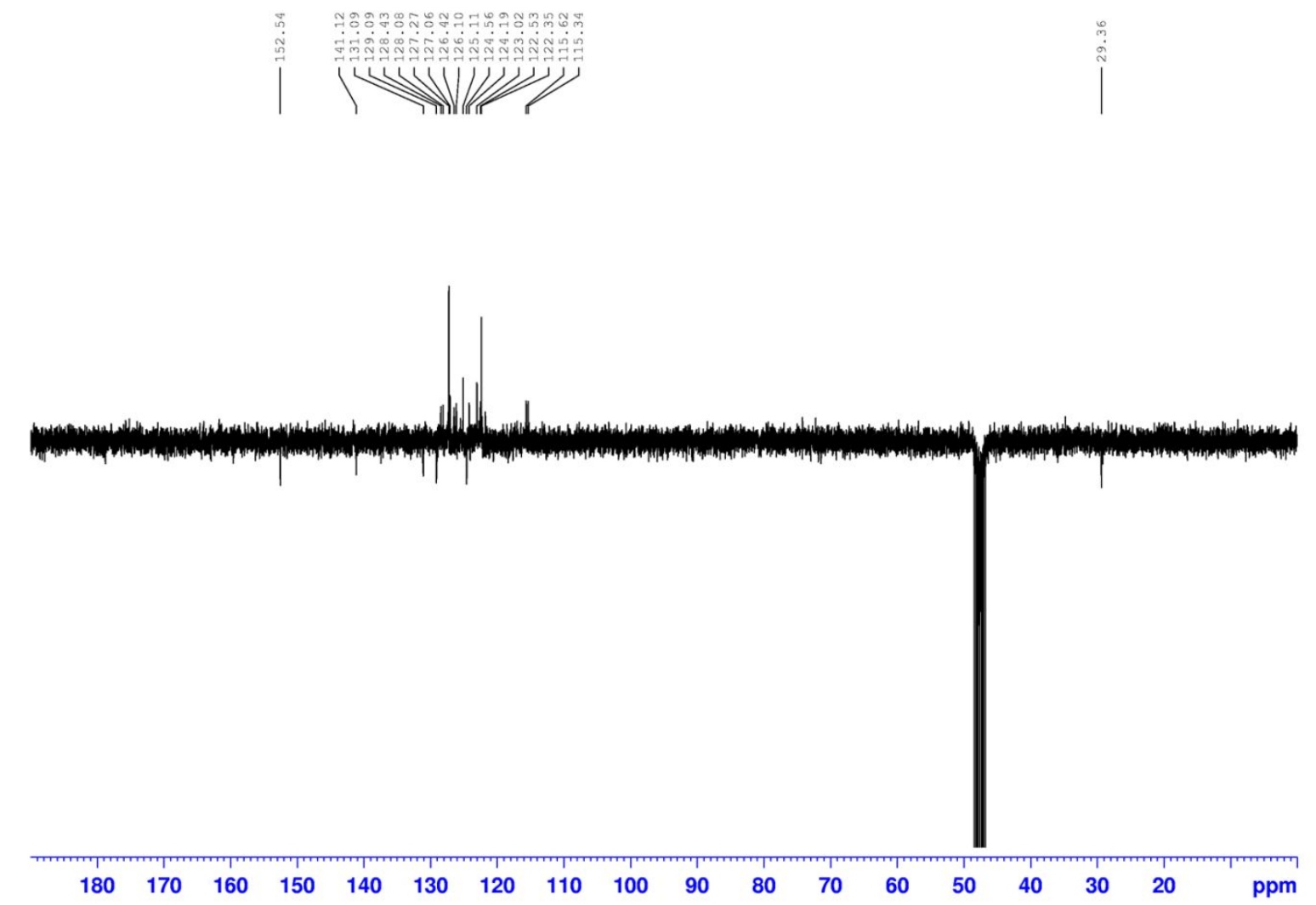

Figure S3. ${ }^{13} \mathrm{C}$ NMR spectra of Schiff base ligand (SBCR) 


$\begin{array}{rlllll} & & \text { Size (d.nm): } & \text { \% Intensity: } & \text { St Dev (d.nm): } \\ \text { Z-Average (d.nm): } 389,3 & \text { Peak 1: } & 405,6 & 86,4 & 172,0 \\ \text { Pdl: } 0,382 & \text { Peak 2: } & 5008 & 7,8 & 606,2 \\ \text { Intercept: } 0,870 & \text { Peak 3: } & 98,90 & 5,8 & 17,16 \\ & \text { Size Distribution by Intensity }\end{array}$

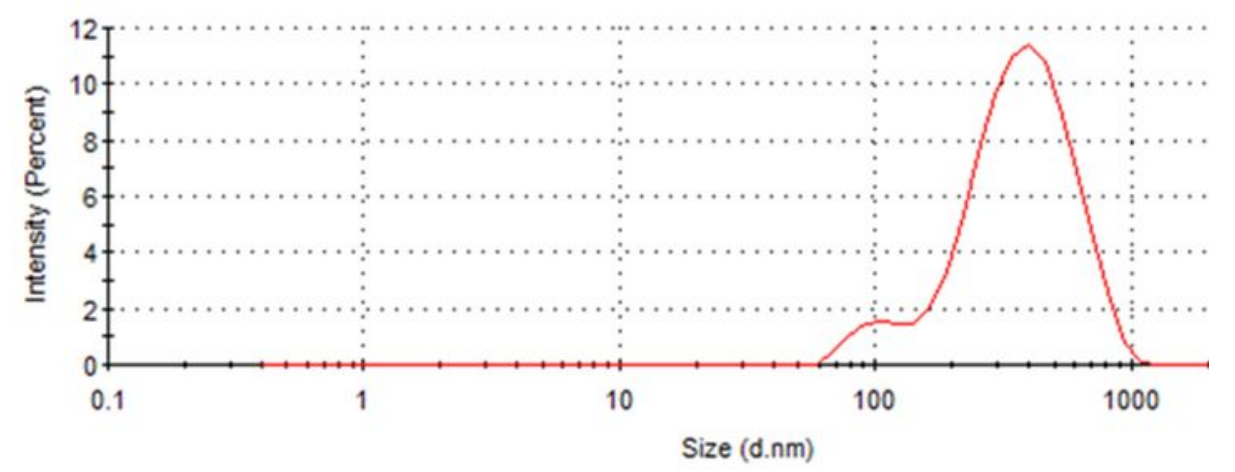

Figure S4. DLS measurement of $\mathrm{Fe}_{3} \mathrm{O}_{4}$ NPs with PDI measurements.

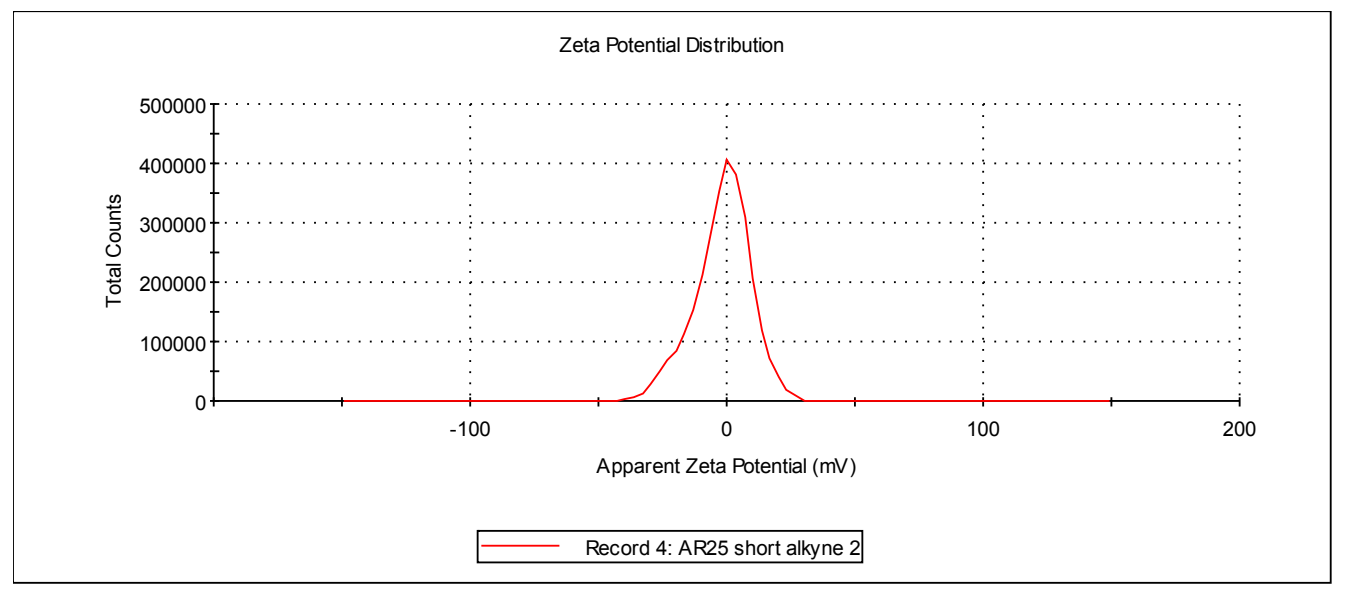

Figure S5. Zeta potential of $\mathrm{Fe}_{3} \mathrm{O}_{4} \mathrm{NPs}$. 


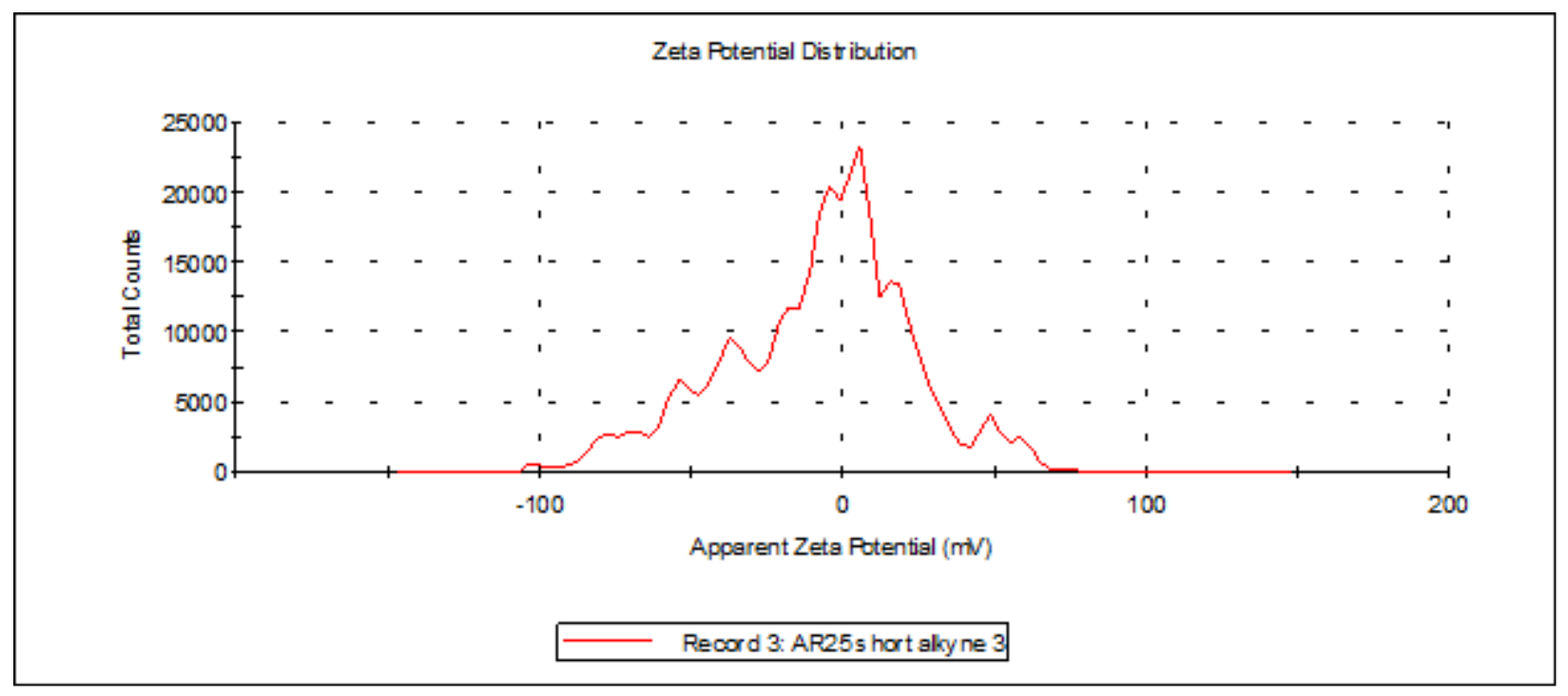

Figure S6. Zeta potential of $\mathrm{CR} @ \mathrm{Fe}_{3} \mathrm{O}_{4} \mathrm{NPs}$.

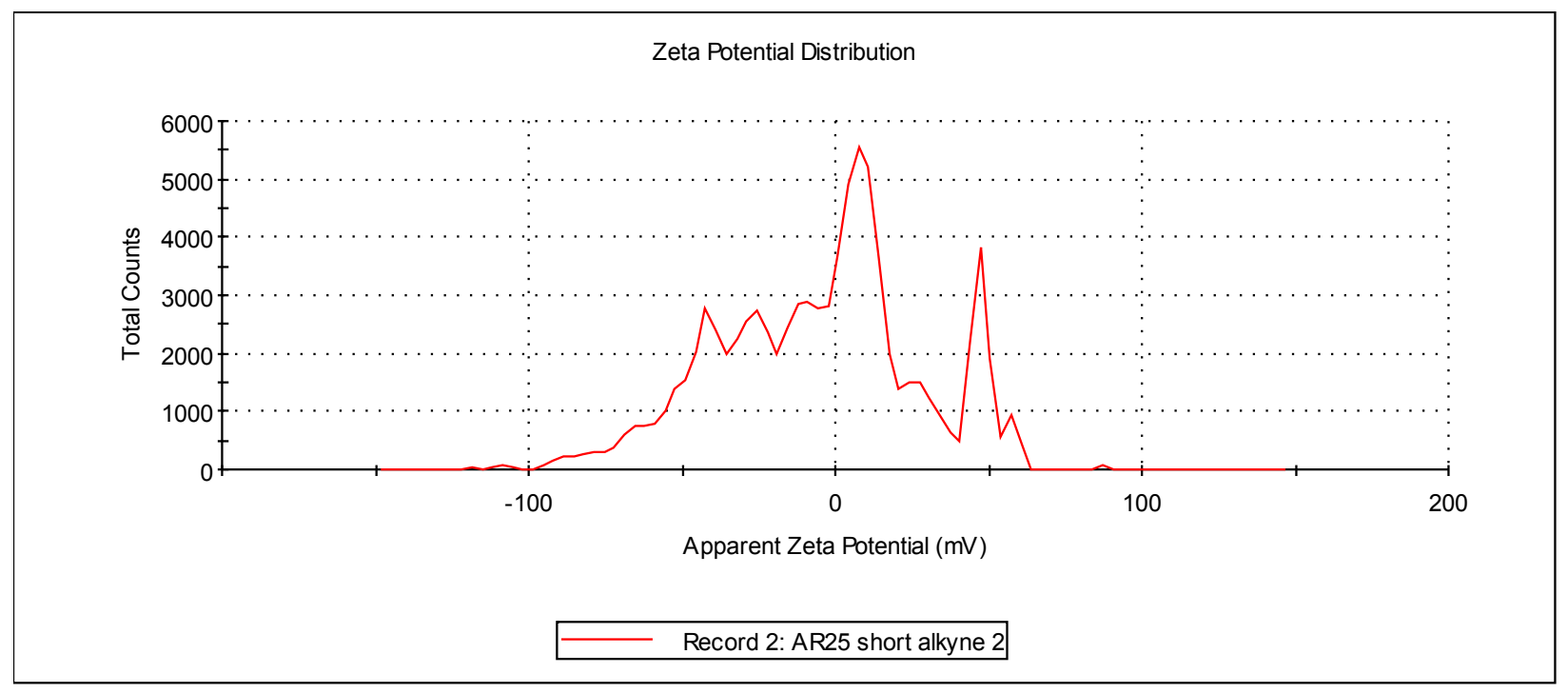

Figure S7. Zeta potential of Congo Red. 


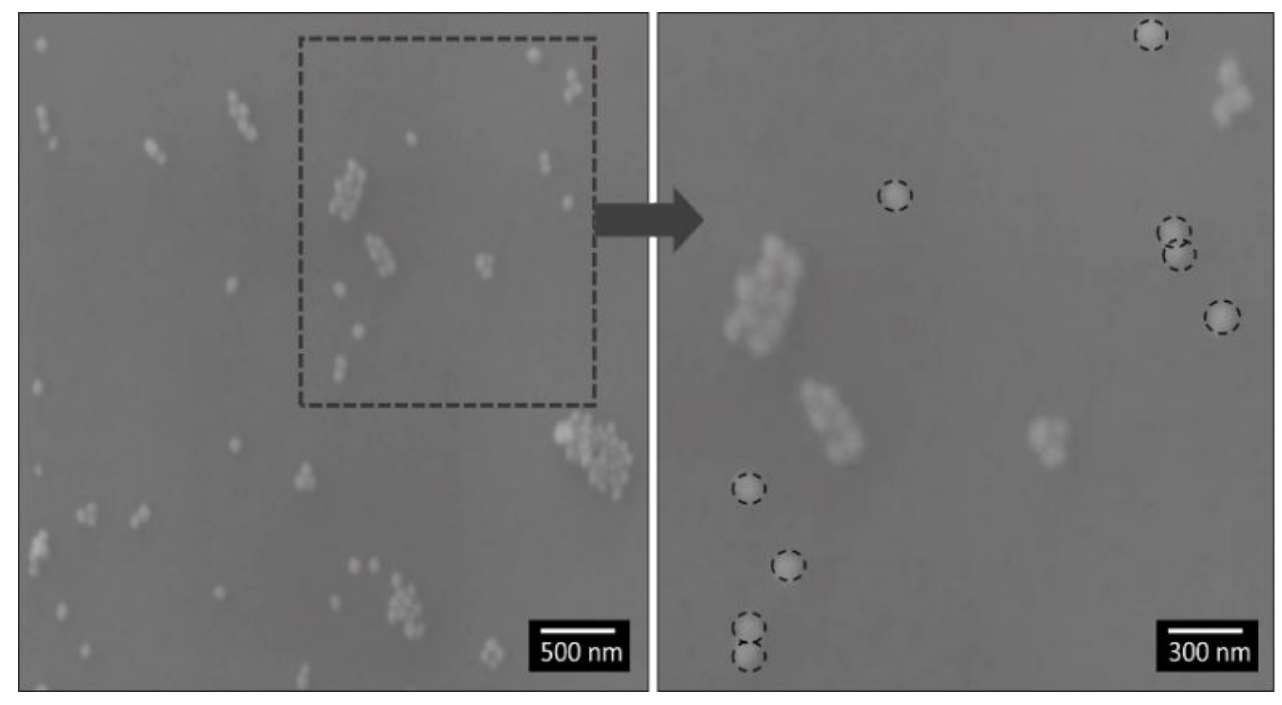

Figure S8. SEM image shows the over view of iron oxide NPs (left), right image displays the closer view of homogeneous spherical NPs. 